\title{
The Relationship between Safety Management and Patient Safety Culture in Cancer Treatment Centers
}

\author{
Mohammad Monfared ${ }^{1}$, Ali Maher ${ }^{1}$, Mehrnoosh Jafari ${ }^{2}$
}

${ }^{1}$ Department of Health Services Management, School of Management, North Tehran Azad University, Tehran, Iran. ${ }^{2}$ Department of Health Services Management, Faculty of Management, North Tehran Azad UniversityTehran, Iran.

\begin{abstract}
Introduction: Enhancement of patient safety represents a principle objective followed by any health system, and it is necessary to consistently monitor the patient safety culture among nurses. Adopted by health service providers, the patient safety culture is described as the acceptance and maintenance of the patient safety as a common priority and value across the organization, or representation of the common patient safety-related values, beliefs, perceptions, and attitudes among the staff at centers providing health services, as expressed in their behaviors. Given the importance of this topic, the present research investigates the state of safety management in the relationship between safety management and patient safety culture in Cancer Treatment Centers, so as to study the patient safety culture among the personnel at the hospitals. Methods: The present research plan is an applied study following a descriptive aim via a correlational methodology. Validity of the questionnaires used in this research was confirmed based on opinions of five experts, with the reliability of the results among the observers confirmed by a Cronbach's alpha of 0.86 . The statistical population included three training hospitals in the city of Kermanshah, where different departments such as management, operating rooms, nurses, and the committee of safety and incidents were investigated during 2017-2018. Results: Based on the findings of the present research, significant direct relationships were observed between the patient safety culture and safety management variables (e.g., operating room standards assessment, the committee of safety and incidents, hospitalization wards assessment, hospital accreditation score, hospital structure, and hospital organization), and an inverse relationship was obtained between the hospital occupancy rate and the patient safety culture. Conclusion: Determination of safety policies by the management, keeping the personnel well-trained, and continuous reports by the personnel tend to enhance the level of safety across a hospital, thereby adding to the safety culture and productivity of the hospital while reducing potential safety risks. Accordingly, in order to enhance patient safety, it is necessary to adequately invest on the assessment of the safety culture.
\end{abstract}

Keywords: Safety management- patient safety culture- accreditation- Patient Safety Friendly Hospitals Standards

Asian Pac J Environment and Cancer, 2 (1), 11-16

\section{Introduction}

There are many costs incurred each year due to occupational accidents, in short, most of them are due to lack of safety. Which in addition to financial losses also leaves irreparable spiritual and human losses [1-9]. Occupational accidents usually occur in hospitals that may be due to neglect, Failure, carelessness, fatigue or other factors, without prior warning. And failure to provide the right health care at the right time will have irreparable consequences [10-12]. If all hospital staff
Submission Date: 01/07/2019 Acceptance Date: 03/09/2019

know that safety and security in the hospital environment and the technical performance of the hospital are at their optimum level, their efficiency will increase dramatically. On the other hand, if these centers are recognized as safe hospitals, they will be successful in attracting the maximum number of other patients [12-14]. The results of Anderson et al.'s research [15] suggest that structural and organizational changes such as staff training systems, hospital information systems, and improved working conditions are necessary to increase patient safety in the hospital. These are successful when

Corresponding Author:

Dr. Ali Maher

Department of Health Services Management, School of Management, North Tehran Azad University, Tehran, Iran.

Email: maher@iau-tnb.ac.ir 
supporting the structure of the hospital and having a strategic plan in place. Maher et al. [16] examined patient safety development strategies in the Ministry of Health. Establishing a strategic patient safety plan is to improve the quality of services provided to patients and ensure their safety. Developing a comprehensive strategy for patient safety is based on accurate information on health system weaknesses, strengths, opportunities, and threats, and then working to implement it in accordance with patient safety principles can help the hospital achieve success. Moufarrej [17] examined in his research the performance of staff and hospital responsibility for safety in Saudi Arabia. The results suggest that hospital and hospital management should have appropriate safety plans in place for the safety of patients and staff. Each hospital should formulate the essentials of its occupational safety programs. In their research, AbuAlRub et al [18] formulated policies to structure staff information to improve safety in Japanese hospitals, and they concluded that to improve hospital safety, hospital information systems need to be more efficient. One of the factors affecting safety management is hospital accreditation rating. Thornlow and Merwin [19] evaluate the relationship between accreditation standards related to patient safety and patient outcomes, and the results showed that the rate of safety index was higher in hospitals with high accreditation score. Another factor affecting the safety management of bed occupancy averages was investigated by Ardalan et al. [20]. The results of their studies showed that there is an inverse relationship between bed occupancy rate and safety. The successful recovery of medical errors indicates a major flaw in the health care industry. Faden et al. [21] examined the impact of leadership and the continuous improvement of the quality of health care services in enhancing patient safety. Their aim is to show how management and structure can improve the safety climate and enhance the quality of treatment services. Kristensen et al. [22] examined the role of human factors and systemic approaches in safety management. According to their results, balancing the work system and encouraging the active and adaptive role of staff are key principles in improving the quality of patient health. Kristensen et al. [22] examined safety status in three areas of organization and management of the Safety and Accidents Committee, evaluation of organization and structure of hospital, and evaluation of operating room standards from a safety management approach. Strategies for enhancing safety in hospitals have included overseeing safety management and continuing training courses, which are needed at the staff level along with their interaction with each other. Safety management in a hospital environment and in therapeutic environments should be practiced in a specific setting. In simple terms, safety management must be done in an environment that exists externally and that the components of the organization are present. An organizational component is organizational culture. Safety management should be applied to a culture of safety that is formed and exists between the components of the organization. In a patient safety culture, staff have a consistent and active awareness of the factors that can go wrong [23]. Safety culture is one of the key determinants of the safety of organizations. Culture of healthcare providers about patient safety is defined as accepting and paying attention to patient safety as the first priority and value common to the organization or as the common values, beliefs, perceptions and attitudes of health care center staff toward patient safety, which manifests in their behavior. In a study of patient safety culture, Ammouri A. et al. [24] found that nurses who received more managerial expectations and opinions, about feedback on work mistakes, had a greater general understanding of patient safety. Also, nurses who had more work experience and worked in educational hospitals were more aware of the patient safety culture. The results showed that continuous training and development, support from hospital management, managerial / supervisory expectations, error feedback and communication, teamwork, and hospital handover were among the predictors of patient safety culture. Caris et al. [25] examined patient safety culture using the HSOPSC questionnaire. The results of their work showed that organizational learning and continuous improvement are accompanied by negative attitude of nurses and need to create a positive safety culture with free communication, mutual belief, shared understanding of the importance of safety and taking preventive measures in this regard. What is important is the emphasis on safety culture as a formal principle in hospitals for the use of nurses. The results of the Richardson et al. Study [26] have shown that adding safety culture to the employment of nurses increases patient safety. In accordance with what was evaluated, improving patient safety is one of the major goals of health systems and it is essential to consider patient safety culture in hospitals as health centers. Patient safety culture describes patient acceptance and consideration of patient safety as a common priority and value in the organization or as a common values, beliefs, perceptions, and attitudes of health care staff regarding patient safety. That is reflected in their behavior. Considering the above mentioned issues and also the importance of the issue of preventable and unwanted safety accidents in medical settings such as hospitals and most importantly, the necessity of planning in this regard, the researcher in this study investigates the relationship between safety management status of Cancer Treatment Centers and the patient safety culture among staff at these hospitals has paid off.

\section{Materials and Methods}

This research is an applied one and descriptive correlation method is used. The time interval was cross-sectional in selected hospitals of Kermanshah University of Medical Sciences. In this research, the researcher first prepared a research plan to study the literature on safety management and safety culture. Then, by extracting the research variables, a questionnaire was designed for statistical samples of research. Then, after distributing and collecting the questionnaire, based on the analysis of their data, conclusions and suggestions 
were presented. To evaluate each of the two main factors (safety management and safety culture), the statements mentioned in the extraction research literature are used.

\section{Safety management}

Safety management variables in this study are: Safety status score, Hospital organization and structure standards score, Safety and incident committee standards score, Operating room standards score, Standards for all hospital wards, Having or not having mandatory safety friendly hospital standards, Average, accreditation score.

\section{Patient safety culture}

Patient safety culture measures twelve dimensions of patient safety culture including the number of reported errors, manager and supervisors' expectations and concerns about safety culture, organizational learning, timework within organizational units, open channels of communication, alerting employees to updates and giving feedback on this, non-punitive response to errors, issues related with psychotherapy, support of hospital management for patient safety, teamwork within hospital units, and data transfer.

In this study, data collected from questionnaire (measured by Likert spectrum) were analyzed using SPSS software and appropriate statistical methods in both descriptive and inferential forms. Descriptive statistics were used to display demographic information and data distribution.

\section{Results}

In this study, three training hospitals were used. The overall characteristics of these three hospitals, such as average occupancy rate, accreditation score, and mandatory safety-friendly hospital standards, have been reviewed. The results of each hospital are summarized in Table 1.

Table 2 presents the results of the evaluation of organization and structure of hospital from a management approach.

Table 3 shows the results of the safety management assessment from the viewpoint of the Safety and Accidents Committee. The Accident and Safety Committee's

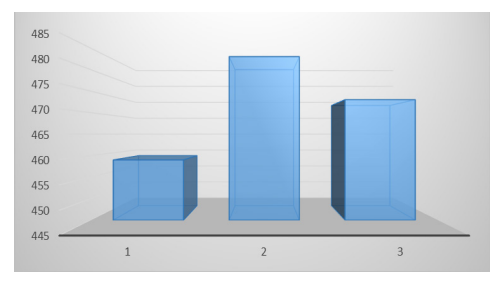

Figure 1. Results of Safety Management Scores of the Hospitals Studied

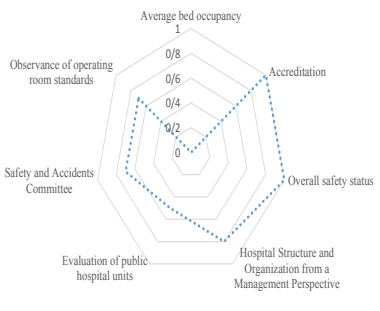

Figure 2. Relationship of Correlation Coefficient between Safety Management Measures with Safety Culture

management of all three hospitals is at an intermediate level. In the Regulations section, two hospitals are in good level and the first one is in intermediate level. In using physical, human and financial resources, acquaintance and continuing education, operation and safety oversight of the hospitals studied are at a moderate level. Managing and monitoring the likelihood of injury, injury, health and safety in hospitals the results show their good level.

A review of the results of the operating room evaluation at the level of organization and management is presented in Table (4) and indicates that Hospitals 1 and 2 are at a good level and Hospital 3 is at a moderate level. In the area of human resources and leadership, all three hospitals are at a moderate level. In terms of policy availability, the rules and regulations of all three hospitals were good. In terms of staff training, they are at a moderate level and in adequate equipment and facilities including operating room amenities, storage space for equipment and access to hospitals were at a moderate to poor level.

The total scores considered in the four roles of the

Table 1. Overall Scores of the Hospitals

\begin{tabular}{lccc}
\hline Hospitals & Last accreditation score & Mandatory standard of patient-friendly hospital safety & bed occupancy Average \\
\hline 1 & 76 & does not have & $81 \%$ \\
2 & 84 & does not have & $85 \%$ \\
3 & 82 & does not have & $99 \%$ \\
\hline
\end{tabular}

Table 2. The Evaluation of Organization and Structure of Hospital from a Management Approach

\begin{tabular}{|c|c|c|c|c|c|c|}
\hline Hospitals & $\begin{array}{l}\text { Organizational } \\
\text { structure of } \\
\text { the hospital }\end{array}$ & $\begin{array}{c}\text { Leadership and staff } \\
\text { development and } \\
\text { continuing education }\end{array}$ & Monitor potential risks & Health and Safety & $\begin{array}{l}\text { Emergency and } \\
\text { Accidents } \\
\text { Preparedness }\end{array}$ & $\begin{array}{l}\text { Points and status of safety } \\
\text { management in the area of } \\
\text { organization and structure }\end{array}$ \\
\hline 1 & 22 & 15 & 25 & 63 & 37 & 162 \\
\hline 2 & 23 & 16 & 21 & 63 & 36 & 159 \\
\hline 3 & 22 & 16 & 25 & 73 & 34 & 160 \\
\hline
\end{tabular}


Table 3. Evaluation of Scores of Safety Management Evaluation Measures in Hospitals Affiliated with the Accident and Safety Committee

\begin{tabular}{|c|c|c|c|c|c|c|c|c|}
\hline hospitals & $\begin{array}{l}\text { Organization and } \\
\text { safety and accident } \\
\text { committee's } \\
\text { management }\end{array}$ & $\begin{array}{l}\text { Regulations } \\
\text { and rules }\end{array}$ & $\begin{array}{c}\text { Human, } \\
\text { physical and } \\
\text { financial sources }\end{array}$ & $\begin{array}{c}\text { Familiarity } \\
\text { and continuing } \\
\text { education }\end{array}$ & $\begin{array}{c}\text { Operation and } \\
\text { monitoring of } \\
\text { safety } \\
\text { management }\end{array}$ & $\begin{array}{c}\text { Manage and } \\
\text { monitor the } \\
\text { likelihood of } \\
\text { damage and losses }\end{array}$ & $\begin{array}{l}\text { Safety } \\
\text { and } \\
\text { health }\end{array}$ & $\begin{array}{l}\text { Total } \\
\text { scores }\end{array}$ \\
\hline 1 & 25 & 29 & 10 & 9 & 9 & 14 & 7 & 103 \\
\hline 2 & 26.5 & 36 & 10 & 13 & 12 & 16.5 & 8 & 122 \\
\hline 3 & 29 & 35.6 & 9 & 13 & 12 & 16 & 8 & 122.6 \\
\hline
\end{tabular}

Table 4. Evaluation of Scores of Safety Management Evaluation Measures in the Operating Rooms of Hospitals

\begin{tabular}{lccccc}
\hline hospitals & $\begin{array}{c}\text { Organization and } \\
\text { safety and accident } \\
\text { committee's } \\
\text { management }\end{array}$ & $\begin{array}{c}\text { Regulations } \\
\text { and rules }\end{array}$ & $\begin{array}{c}\text { Human, physical } \\
\text { and } \\
\text { financial sources }\end{array}$ & $\begin{array}{c}\text { Familiarity and } \\
\text { continuing education }\end{array}$ & $\begin{array}{c}\text { Operation and } \\
\text { monitoring of safety } \\
\text { management }\end{array}$ \\
\hline 1 & 53 & 26 & 26 & 17 & 20 \\
2 & 50 & 25 & 27 & 16 & 21 \\
3 & 47 & 24 & 24 & 16 & 142 \\
\hline
\end{tabular}

Table 5. Total Scores of Hospital Safety Management

\begin{tabular}{lccc}
\hline & Hospital 1 & Hospital 2 & Hospital 3 \\
\hline Total scores & 459 & 483 & 473 \\
\hline
\end{tabular}

organization and structure hospital, the incident committee, the operating room standards, and the evaluation of public units as the overall safety management score in each hospital are reviewed. As the hospital's rankings are shown in Figure (1).

The relationship between safety management dimensions and safety culture using Spearmett's correlation coefficient is shown in Table (6).

Table (6) shows that the correlation coefficient is positive and significant in all cases except the average bed occupancy. Correlation coefficient is negative for average bed occupancy and not significant at $95 \%$ confidence level. Figure (2) shows the correlation coefficient of safety management measures with safety culture.

\section{Discussion}

The purpose of this study was to investigate the relationship between safety management and safety culture in selected hospitals of Kermanshah Medical Sciences. As Table 6 shows, there is a significant relationship between overall safety status and hospital safety culture. This was in line with the results of previous studies including Pronovost et al. [27] and Ammouri et al. [24]. It should be noted that, given the importance of safety culture dimensions such as overall understanding of safety, and patient safety issues in terms of staff and management, this relationship and its significance are plausible. In addition, the results showed that there is a significant relationship between hospital structure and organization in terms of management and safety culture and the correlation between these two factors is in a way that increasing one variable leads to another increasing. In explaining this finding, it can be pointed out that when leadership and management are committed to a safety culture, the whole organization adheres to them, thus increasing the disclosure of incidents and the overall understanding of employees about safety. The findings also indicate that the relationship between status of safety and accidents committee and safety culture shows a positive correlation between these two variables. which is significant at the level of confidence considered. Given that the committee's policies are to set specific safety policies, establish management and personnel oversight to increase safety, as well as monitor potential risks. The actions of this committee can be effective in raising expectations and management measures to improve patient safety, supporting patient safety management and enhancing teamwork between hospital units. This affects the safety culture in the organization.

Table 6. Results of Correlation of Safety Management Measures with Safety Culture

\begin{tabular}{lcc}
\hline Variables & $\begin{array}{c}\text { Safety Culture } \\
\text { Correlation coefficient }\end{array}$ & significant \\
\hline Hospital Structure and Organization from a Management approach & $0.770^{*}$ & 0.015 \\
Safety management from the Safety and Accidents Committee approach & $0.666^{*}$ & 0.036 \\
General assessment of hospital wards & $0.406^{*}$ & 0.040 \\
Evaluation of operating room standards & $0.644^{*}$ & 0.001 \\
Bed occupancy average & -0.5 & 0.667 \\
Accreditation score & $1^{*}$ & 0.001 \\
Overall safety status & $1^{*}$ & 0.001 \\
\hline
\end{tabular}


That these findings are consistent with those of Rezapoor et al. [1], Sabzghabaie et al. [28] in the field of safety culture. By analyzing the information in Table 6, the correlation between the status of operating room standards and safety culture was evaluated positively. This result is consistent with the paper by, Safazadeh and Zarei, Behzadi et al. [29], And Caris et al [25]. In explaining this result, it can be said that the operating room is a sector that pursues specific goals, and since this sector is particularly concerned with people's health and the community is particularly sensitive to it, safety performance and safety culture in This unit has a great role to play. Patients' relationship with nurses, patients' awareness of rules, division of tasks and balance of power shifts are among the most important issues that influence nurses' viewpoints on patient safety culture that can be aligned with teamwork between units, issues related to staffing and the opening of communication channels. According to the results of the analysis of the data obtained from this ward, there is a positive correlation between the status of hospitalized wards with safety culture, which is true according to what was said. Implementation of patient safety standards, including mandatory, basic and advanced standards, has not been implemented in any of the three hospitals, which has been removed from the review with a safety culture. The results of Spearman correlation analysis between the two variables showed that there is no significant relationship between these two factors, which can be attributed to the fact that the discussion of safety and culture is influenced by different factors. The obtained coefficient is negative in two variables and with the decrease in the number of patients, the patient's safety culture is growing, which is possible due to the interactions between staff and patients and the implementation of safety policies and management strategies to enhance safety culture. Accreditation is also a good strategy to improve the quality of health services, reduce medical errors, improve patient safety and improve hospital performance. the results of correlation between hospital accreditation score and safety culture have a direct relationship between these two variables, so that accreditation leads to strengthening patient safety culture in hospital. Hospitals managers explicitly set the rules, regulations, policies, and procedures for the implementation of accreditation standards, and encourage staff to use clinical protocols and guidelines. The implementation of accreditation standards strengthens collaboration between different hospital professionals and improves the satisfaction of physicians, nurses and other health care providers. Accreditation develops individual and organizational learning and facilitates intra- and interorganizational communication.

In conclusion, the results of the present study showed that there is a direct and significant relationship between the details of safety management including hospital structure and organization from management perspective, safety management from the viewpoint of safety and accidents committee, evaluation of operating room standards, status of hospitalized wards and accreditation score with patient safety culture. And by increasing any of the safety management measures, the patient safety culture can be reciprocally increased, and there is a reverse relationship between the average hospital bed occupation and patient safety culture. The studied conditions show moderate and good level of safety management in the studied hospitals and, in terms of patient safety culture, they are at a moderate level and can improve patient safety culture by increasing the level of hospital safety management.

\section{Recommendation}

The present study showed that in most variables of patient safety management there is a significant relationship with patient safety culture. The punitive culture at work, issues regarding the number and distribution of staff and hours of work, manager support for patient safety, and how communications are the most important issues require attention in these hospitals. It is suggested that by changing the existing culture of hospitals where individuals are blamed and punished for wrongdoing, create a climate where employees report their errors without fear of reprisal and punish, and provide an opportunity for themselves and their colleagues to learn from these mistakes. Patient safety should also be a strategic priority for policy makers in the health system. and in order to improve patient safety and evaluate safety culture, health care organizations should invest. Patient safety standards are a set of requirements that are critical to their implementation in any hospital. evaluation of this process is an advanced mechanism in hospitals that is performed to determine patient safety levels and can be used to initiate and evaluate the progress of ongoing programs. It seems that by creating a competitive environment for hospital managers, their motivation and effort to implement patient safety programs is increased. It seems that by creating a competitive environment for hospital managers, their motivation and effort to implement patient safety programs is increased. and, by focusing patients on service delivery, training staff and patients, removing legal barriers and increasing compliance requirements, safety-friendly hospitals should be increased. However, the hospitals studied had overall good performance in patient safety, but in a separate review of each hospital, we saw their shortcomings and their gap with standards. Hospitals should target with proper management, and move forward with a strategic plan to achieve the goals to compensate deficiencies.

\section{References}

1. Rezapoor A, Tanoomand Khoushehmehr A, Bayat R, Arabloo J, Rezapoor Z. Study of patients' safety culture in Selected Training hospitals affiliated whith Tehran university of medical sciences. Journal of Hospital. 2012;11(2):55-64.

2. Nourmohammadi M, Asadi AF, Jarrahi AM, Yari S. Risk of Mortality Caused by Silicosis and Lung Cancer: a Study on Ceramic Tile Factory Workers. Asian Pacific Journal of Environment and Cancer. 2018;1(2).

3. Yari S, Pouyakian M, Jafari MJ, Alipour A, Varmazyar S. Preparation and psychometry of a safety assessment questionnaire for urban gas stations. Safety Promotion and 
Injury Prevention. 2018;5(3):169-80.

4. Yari S. Inherent safety design in compose of urban gas station. Safety Promotion and Injury Prevention. 2015;3(2):135-40.

5. Normohammadi M, Kakooei H, Omidi L, Yari S, Alimi R. Risk assessment of exposure to silica dust in building demolition sites. Safety and health at work. 2016;7(3):251-5.

6. Yari S. Assessment of potential risk by the failure mode and effects analysis in an air conditioning equipment manufacturing company. Journal of Safety Promotion and Injury Prevention. 2017;5(2).

7. Yari S, Fallah AA, Varmazyar S. Assessment of semiquantitative health risks of exposure to harmful chemical agents in the context of carcinogenesis in the latex glove manufacturing industry. Asian Pacific journal of cancer prevention: APJCP. 2015;17(205):11.

8. Yari S, Asadi AF, Jarrahi AM, Normohammadi M. CARcinogen EXposure: CAREX. Asian Pacific Journal of Environment and Cancer. 2018;1(1).

9. Yari S, Asadi AF, Normohammadi M. Occupational and Environmental Cancer. Asian Pacific Journal of Environment and Cancer. 2018;1(1).

10. Safety WP, Organization WH. WHO guidelines for safe surgery: 2009: safe surgery saves lives. Geneva: World Health Organization; 2009.

11. Yari S, Akbari H, Gholami Fesharaki M, Khosravizadeh O, Ghasemi M, Barsam Y, et al. Developing a model for hospital inherent safety assessment: Conceptualization and validation. International Journal of Risk \& Safety in Medicine. 2018;29(3-4):163-74.

12. Yari S, Naseri MH, Akbari H, Shahsavari S, Akbari H. Interaction of Safety Climate and Safety Culture: A Model for Cancer Treatment Centers. Asian Pacific Journal of Cancer Prevention. 2007;20(3):961-9.

13. Sari AB-A, Sheldon TA, Cracknell A, Turnbull A. Sensitivity of routine system for reporting patient safety incidents in an NHS hospital: retrospective patient case note review. Bmj. 2007;334(7584):79.

14. Normohammadi M, Asadi AF. Job Stress and Safety Climate in Cancer Treatment Centers: Upgraded Model for Dimensions. Asian Pacific Journal of Environment and Cancer. 2018;1(2).

15. Anderson E, Thorpe L, Heney D, Petersen S. Medical students benefit from learning about patient safety in an interprofessional team. Medical education. 2009;43(6):54252.

16. Maher A, Ayoubian A, Sheibani Tehrani D, Rafiei S. Developing Strategies for Patient Safety Implementation: A National Study in Ministry of Health and Medical Education. 2018.

17. Moufarrej MN, Mahfoud Z, Badsha H. Barriers to achieving controlled rheumatoid arthritis in the United Arab Emirates: a cross-sectional study. Rheumatology international. 2015;35(4):759-63.

18. Wu Y, Fujita S, Seto K, Ito S, Matsumoto K, Huang C-C, et al. The impact of nurse working hours on patient safety culture: a cross-national survey including Japan, the United States and Chinese Taiwan using the Hospital Survey on Patient Safety Culture. BMC health services research. 2013;13(1):394.

19. Thornlow DK, Merwin E. Managing to improve quality: the relationship between accreditation standards, safety practices, and patient outcomes. Health care management review. 2009;34(3):262-72.

20. Ardalan A, Kandi M, Talebian MT, Khankeh H, Masoumi G, Mohammadi R, et al. Hospitals safety from disasters in IR iran: the results from assessment of 224 hospitals. PLoS currents. 2014;6.

21. Faden RR, Kass NE, Goodman SN, Pronovost P, Tunis S, Beauchamp TL. An ethics framework for a learning health care system: a departure from traditional research ethics and clinical ethics. Hastings Center Report. 2013;43(s1):S16-S27.

22. Kristensen S, Mainz J, Bartels P. Selection of indicators for continuous monitoring of patient safety: recommendations of the project 'safety improvement for patients in Europe'. International Journal for Quality in Health Care. 2009;21(3):169-75.

23. Smits M, Christiaans-Dingelhoff I, Wagner C, van der Wal G, Groenewegen PP. The psychometric properties of the'Hospital Survey on Patient Safety Culture'in Dutch hospitals. BMC health services research. 2008;8(1):230

24. Ammouri A, Tailakh A, Muliira J, Geethakrishnan R, Al Kindi S. Patient safety culture among nurses. International Nursing Review. 2015;62(1):102-10.

25. Caris MG, Kamphuis PG, Dekker M, de Bruijne MC, van Agtmael MA, Vandenbroucke-Grauls CM. Patient safety culture and the ability to improve: a proof of concept study on hand hygiene. infection control \& hospital epidemiology. 2017;38(11):1277-83.

26. Richardson A, Storr J. Patient safety: a literative review on the impact of nursing empowerment, leadership and collaboration. International nursing review. 2010;57(1):1221.

27. Pronovost PJ, Weast B, Bishop K, Paine L, Griffith R, Rosenstein BJ, et al. Senior executive adopt-a-work unit: a model for safety improvement. The Joint Commission Journal on Quality and Safety. 2004;30(2):59-68.

28. Sabzghabaie A, Kondori A, Shojaee M, Hatamabadi H, Amini A. Hospital safety in hospitals affiliated with Shahid Beheshti University of Medical Sciences in 2011-13. Pajoohandeh Journal. 2013;18(2):83-7.

29. Janghorbani M, Raisi A, Dehghani S, Mousavi A. Assessment of Safety Status in Operating Rooms of Shahid Beheshti Hospital, Isfahan, Iran by the World Health Organization Standards for Safety-Friendly Hospitals. 2013. 2013.

\section{(i) ()}

This work is licensed under a Creative Commons AttributionNon Commercial 4.0 International License. 